\title{
The hehaviour of a large dam at severe frost
}

\author{
P. CALOI $(*)-$ M. Migani $(* *)-$ M. C. Spadea $(*)$
}

Received oII May 5th, 1972

Summary. - Synthesizing the problem, the action of the thrusts in the behaviour of the dam of Pieve di Cadore, makes itself conspicuous expecially during three periods of the year:

1. - About the end of June, the air temperature, on the average, overcomes the water one in the watershed upstream the dam: the bending of the dam upstream increases from the bottom to the top.

2. - About the end of October, the thermal conditions change; the mean air temperature grows lower than the mean water temperature; the dam begins her bending dowstream.

3. - When the air temperature is distinctly below $0^{\circ} \mathrm{C}$, the action of the thrusts grows more complexe; the rocky waterlogged system downstream of the dam, while cooling, swells and pushes the bottom of the dam upstream; at the higher quote, on the contrary, the thrust downstream continues.

When the strenght limit of the medium is surpassed, arises a contrast between the rocky system and the concrete structure: this contrast can originate very small fractures, revealed from seismic station installed into the central ashlar (XIV) at 660 metres height of the dam, under the form of microshocks which energy is of about $10^{10}-10^{11} \mathrm{erg}$.

1. As is known, the behaviour of a dam above $0^{\circ} \mathrm{C}$ may be synthezised into two principal movements due to the action of temperature variations: an upstream bending movement if temperature rises and a downstream flexure if temperature decreases $\left(^{1}\right)$. This does not take into account, of course, the variations depending on the watershed. At about $0 \circ \mathrm{C}$ and below the behaviour of a dam becomes more complex.

Upstream of the barrage the lake covers the dam up to a certain height. When the temperature falls below $0^{\circ} \mathrm{C}$, the water level at

(*) Istituto Nazionale di Geofisica, Roma.

(**) E.N.E.L. Compartimento di Venezia. 
the surface freezes to a certain thickness according to the negative thermal stage. Below the frozen layer the water maintains a temperature above 0 or. The situation downstream depends on the outer temperature which is more or less, but distinctly below $0{ }^{\circ} \mathrm{C}$. This means that the portion of the dam which is covered by the water has a higher temperature than the portion downstream. This adds at least in the beginning - to the thrust of the dam downstream.

But if the temperature of the air remains for a longer time period distinctly below $0 \circ \mathrm{O}$, new factors enter into action due to the abnormal behaviour of the frozen soil. The rocky system on which the dam foots is obviously waterlopped down to a certain depth. When the temperature remains sizeably below 0 oc for several days, the frost penetrates more or less deeply into the underground downstream of the dam. While freezing, the liquid component brings about a swell of the soil which is all the more pronouncerl the deeper the frost penetrates. At the margins of the plain in contact with the dam, a thrust is therefore developing toward the barrage, annulling the opposite thrust from the submersed surface and causing at last an upstream bending of the dam bottom. Referred to height, in fact, the barrage is subject to the swelling action of the springer rocky merlium only in the narrow area corresponding to the dam thickness. Obviously, this action is not strong enough to cause a sizeable thrust from downstream to upstream, so that above the level of the plain outside the dam the downstream thrust makes itself more and more felt, as sketcherl in fig. 1 .

That the effects are such as above described is proved by the clinographic recordings which were obtained under the said conditions at various heights of the central ashlar of the Pieve di Carlore Dam, namely on the levels of the dam bottom (Pian delle Ere) $625 \mathrm{~m}$, $660 \mathrm{~m}$ and on the dam top $(682 \mathrm{~m}$ ) (fig. 2).

2. So far the rock and the concrete have withstood the stress in action within the limits of their proper strength, but when frost persists as far as time, and hence, space is concernerl, the intensity of thrust of the springer rock increases downstream of the dam, toward the barrage. The rheological behaviour of the frozen soil is still far from being discovered in all its aspects. In any case it is highly important in several geomorphological structures (7).

Specific research work conducterl by the Disaster Prevention Research Institute of the University of Kyoto $\left({ }^{\theta}\right)$ have shown - through 
tests of axial compression on frozen soil specimens extracted from various depths of the Plain of Tokyo - that the highest values obtained from clay sediments were between 10 and $20 \mathrm{~kg} / \mathrm{cm}^{2}$ at -5 o $\mathrm{C}$ and above $20 \mathrm{~kg} / \mathrm{cm}^{2}$ at $-10 \circ \mathrm{C}$. The deformation of sedimentary sands at the same temperatures was even stronger, and for rocky grounds the values may rise still higher.

Inversely, if the other conditions remain unchanged, the lateral thrust of a highly frozen medium therefore increases. Besides, if the upstream thrust of the surface layers of the dam plain is counteracted by the downstream thrust of the dam bottom properly speaking which is under the lake, such as is the case with the Pieve di Cadore Dam, an increasing contrast is building up as the frost becomes harsher until the strength limit of the medium is surpasserl, the equilibrium breaks and the medium cracks.

3. This phenomenon assumed spectacular aspects during the first period after the dam building. The seismographs installed in a small house on the right abutment at some fifty metres from the dam recorded thousands of small shocks in the first winters. The recordings were equally given afterwards when the tern Ishimoto seismographs had been installed in the control cabin at close by the dam $\left({ }^{2}\right)$, still on the same side (they were later replaced by a stronger tern of Girlanda seismographs). Most of those small shocks came from the barrage bottom $\left(^{(1,2}\right)$.

After a few years the seismic station installed in the basement of the control cabin stopped recording microshocks coming from the barrage bottom.

Caloi, who had followed the phenomenon since its outset, had got conviction, however, that it could not be altogether spent. Only a seismic station installed within the dam structure could solve the problem. After permission from the "ENEI, ", a "Girlanda " seismic station was installed by Dr. Migani in a staple pit of the central ashlar (XIV) at 660 metres height of the dam (Figs 3,4). With the help of this station, which allowed to detect new phenomena, partly discussed elsewhere and partly covered later hundreds of very small shocks could be revealed during days of very strong frost (see fig. 5) which the station in the centralized control cabin is unable to recorl.

Here arises the spontaneous question why at the start the microshocks were so much stronger that they could be clearly recorded by the thousands even outside the dam. The reply is ob- 
vious: at the outset there were two media, the rocky system and the dam, each with its own characteristics. The forced "symbiose" between the two could not but lead to initial contrasts of a certain violence, capable of reducing the strongest resistance of the rock against the movements of the dam. Therefore, the shattering became more widespread and hit the elements of major size, which explains the higher amounts of energy set free by the microshocks. Furthermore, it was only in this way that the system could settle with new positions of equilibrium (it should not be overlooked in this regard that the modulus of elasticity of the rocky system supporting the plain downstream of the dam was strongly reduced within few years, the first, falling from the initial $7000 \mathrm{~m} / \mathrm{sec}(1949)$ to $5000 \mathrm{~m} / \mathrm{sec}(1960)$ of longitudinal wave velocity $\left({ }^{4}\right)$ ).

After the acute stage of the crisis in the contact surface between the underlying strata of the barrage and the concrete had been overcome, the micromovements of the latter could swing out in the plastic field. This cannot happen in periods of strong frost which, for the above reasons, give rise to shears and elastic waves.

Fig. 6 give numerous examples of microshocks, recorded between December 1970 and March 1971, that is in periods when temperatures fell decidedly below zero degrees (*). We have reported only some of them, of course, but they give sufficient evidence of the large variety of aspects they are assuming, sometimes with considerable unlikenesses between them. Unlikeness indicates different origin and different propagation. Rupture of equilibrium can take place slightly distant from the dam bottom. Due to the limited amount of energy involved, it is unable to cause a shaking of the structure and acts merely as a vehicle of the elastic waves, so as to bring about, in these cases, very fast oscillations which fade away in intervals of one or two seconds (fig. 6). If the crush is closer to the dam, its energy

(*) It would not be surprising if some superficial observation attributed the microshocks to the cracks which from time to time are produced in the iced stratum of the lake. Without mentioning that cracks are not frequent and of a rather limited number, it should be considered that due to continuous variations of the water level in the basin the ice layer appears fractured to a large extent, that is the strip along the watersides. To these, therefore, it is not attached rigidly, so that the energy set free from crackings is dispersed and reaches the waterside in very limited amounts. 
may be such as to cause shakings. Since the excitation energy is into finite medium, it is similar to the oscillations of a diapason: in other words, there will be an anomalous dispersion, with oscillations of longer and longer periods which are the latest and are approaching the uninodal values of the ashlars and often of the dam itself (fig. 6). It is to be noted in this respect that the free oscillations of the structure originate sometimes immediately after the beginning of the perturbation, but sometimes they appear after certain time intervals. This means that the distance from the observation station (installed, in this specific case, at the centre of the dam) to the disturbing area varies. The fact should bo underlined, as well, that often the recording does not show the proper features of a separate microshock, but of several shocks originating at short time intervals between each other, as though the rupture of equilibrium in one point brought about analogous ruptures all about (fig. 6). We reserve to deal more specifically with the principal aspects of the recordings in a following paper.

4. Without considering the barrage bottom which is particularly, if not exclusively, sensitive to the variations of the water basin, the cycle of bendings of a large dam is governed, therefore, by the development of the Seasons - all other conditions remaining equal - and particularly by the anomalous behaviour of the water with regard to the variations of temperature.

This may be summarized as follows. Let us consider a dam (in our specific case the Pieve di Cadore Dam) with the adjacent watershed at a normal level. At a certain date of the first months of the year (which may be February or March, according to the proceeding of the Season), the water and the air will come to have approximately the same mean temperature. After that date, toward Spring, the air beings to be warmer than the water. It will be remembered that water has the highest specific heat of all known substances, which implies that its warming up takes place very slowly, also as far as the dam supporting rock system is concerned. The increase of the gap of mean temperatures of air and water is responsible for a stronger heating up of the wall downstream of the dam compared with the upstream wall which is under the water, with the consequence of a barrage bending upstream which increases in the following months, usually until September inclusively. Besides, to this slow upstream bending adds the diurnal wave following the sun radiations through the 24 hours. 
In the course of these months the water has continued storing up heat, with temperatures of the surface layers going up to maxima of $20^{\circ} \mathrm{C}$. As slowly as heat has been stored, as slowly the water conveyes around. So, when the outer temperature begins to fall, the mean air temperature soon falls below the water temperature of the lake. This is when the thermal condition of the dam walls is inverted: the North wall is warmer than the South wall. And the bending is inverted, too, being directed toward the valley. As the temperature falls further towards $0^{\circ} \mathrm{C}$, the water of the watersherl begins to be subjecterl to a continuous mixing process. The surface water cooling off, becomes heavier and sinks a few metres down. It is replaced by warmer water from major depths. The outer conditions permitting, this phenomenon can go on until a complete blending of the lake water is reached, with temperatures at the lake bottom of about $4^{\circ} \mathrm{C}$ where, as is known, water has the maximum density and, hence, the maximum specific weight. If this situation is to take place, the outer temperature must be clearly below $0{ }^{\circ} \mathrm{C}$, which means the shaping of an ice layer on the lake surface, the continous bending on the entire dam toward the valley, as was described at the beginning, and - frost being strong the observation of the above indicated phenomenon on a part of the lam, that is the bottom, which bends upstream, while the higher portion is always stressed in the opposite direction.

The above describes the phenomenon in its simplest aspects, of course, where the factors involved vary uniformly in one versus only. In fact, there are complications depending on recurrences of Seasons to which the air temperature is particularly sensitive. The response of the dam is immediate: bendings are inverting more or less outspokenly, more or less long or regular, according as the cause evolves. No consideration has been given, of course, to simultaneous actions on the valley as a whole, on its solid parts. The valley tends to shrink in the warm season and to expand in the cold season. Not to mention at all, at last, the contrasts following the more or less marked variations of the water level in the reservoir. 


\section{REFERENCES}

(1) Calor P., 1953. - Osservazioni sismiche e clinografiche presso grandi dighe di sbarramento. "Annali di Geofisica ", VI, 3.

(2) Caloi P., 1962. - La Cieofisica e le grandi dighe. "L'Energia Elettrica", XXXIX, 1 .

(3) Caloi P., 1962. - Aspetti della dinamica di rocce, calcestruzzo ed acque. "Annali di Geofisica", XV, 2-3. (Contiene un'ampia bibliografla su precedenti lavori dell'A. sull'argomento).

(') Calor P., Spadea M. C., 1966. - Principali risultati conseguiti durante l'osservazione geodinamica, opportunamente estesa nel tempo, di grandi dighe di sbarramento, e loro giustificazioni teoriche. "Annali di Geofisica ", XIX, 3.

$\left.{ }^{5}\right)$ Caloi P., Spadea M. C., 1969. - Sulla risposta elastica delle dighe e sulla sua variazione nel tempo. "Annali di Geoflsica", XXII, I.

(5) Fukuo Y., 1966. - On the Rheological Behavior of Frozen Soil (I'art I). "Bull. Disaster Prevention Res. Inst. ", 15, part 3.

(i) Scheidegger E. A., 1970. - Theoretical Geomorpholog!/. Seconda Edizione riveduta. Springer-Verlag. Berlin, pp. 375-382. 